\title{
A WebQuest e a Taxonomia Digital de Bloom como uma nova coreografia didática para a educação online
}

Rogério Antonio de Paiva

Maria Auxiliadora Soares Padilha

\begin{abstract}
Resumo
Este artigo discutirá a metodologia da WebQuest (WQ), quanto a suas críticas, variedades, proposições e principais elementos estruturadores com o objetivo de situá-la no contexto das medias da Web 2.0 conforme a proposta da Taxonomia Digital de Bloom. Para isto discutiremos os questionamentos e proposições feitas a esta metodologia analisando uma parte da estrutura da WebQuest, a tarefa, de um curso de Educação a Distância, a partir das coreografias didáticas e da Taxonomia de Digital Bloom, que é uma atualização da Taxonomia de Bloom. A relevância deste artigo se dá no sentido de ampliar possibilidades pedagógicas no processo de ensino e aprendizagem online como também em desenvolver parâmetros que favorecem a construção de metodologias mais significativas no ensino online. $\mathrm{Na}$ análise da tarefa da WQ estudada se percebe que esta não segue os padrões mínimos de qualidade no tocante à Taxonomia Digital de Bloom, o que nos leva a considerar a metodologia analisada como uma WebExercise.
\end{abstract}

Palavras-chave: Educação Online, WebQuest, Web 2.0, Taxonomia Digital de Bloom.

\footnotetext{
Abstract

The WebQuest Taxonomy and Digital Bloom as a new teaching choreography for online education

This article will discuss the methodology of the WebQuest (WQ), as its critics, varieties, propositions and main structural elements in order to situate it in the context of Web 2.0 media as the proposal of Bloom's Digital Taxonomy. For
} 
this we will discuss the questions and propositions made to this methodology by analyzing a portion of the structure of the WebQuest, the task of a Distance Education course, from the choreography and teaching Digital Bloom's Taxonomy, which is an update of Bloom's Taxonomy. The relevance of this article happens to broaden educational opportunities in the teaching and learning online as well as to develop parameters that favor the construction of methodologies in teaching online.Na most significant task analysis of WQ studied one realizes that this does not follow minimum quality standards in relation to Bloom's Digital Taxonomy, which leads us to consider the methodology considered as a WebExercise.

Keywords:OnlineEducation,WebQuest,Web2.0,Bloom'sDigitalTaxonomy.

\section{Introdução}

O objetivo deste artigo é apresentar uma discussão sobre o uso da metodologia WQ no contexto da modalidade à distância. A motivação para este estudo vem da compreensão de que a Educação a Distância (EAD) vem crescendo vertiginosamente e, com ela, a criação e experimentação de metodologias específicas para esta modalidade. Neste cenário, a WQ, é uma metodologia que pode ser utilizada em cursos à distância para facilitar a aprendizagem a partir de processos investigativos, mas para tal, talvez exija adaptações(Dodge, 2002).

Entendemos, assim, que as WQs são excelentes estratégias de ensino e aprendizagem que precisam ser mais exploradas na modalidade de educação online. Entretanto, é preciso compreender que cada metodologia deve ser apropriada e adaptada ao contexto em que é desenvolvida, por isso, buscamos na Taxonomia Digital de Bloom(Churches, 2009) uma forma de compreender melhor esta proposta a partir de seu contexto mais específico: a internet e os recursos digitais.

A metodologia WQ foi criada em 1995 por Bernie Dodge, professor universitário da Califórnia. Esta metodologia tem como objetivo orientar a pesquisa na Web utilizando recursos prioritariamente das redes. Desde sua criação, entretanto, esta proposta tem sido alvo de muitas críticas, mas também de muita aceitação.

Considerando que a metodologia da WQ é usada em processos colaborativos de aprendizagem e que valoriza o diálogo e a participação dos envolvidos, acredita-se que o uso da WQ se apresentará como um excelente e criativo roteiro metodológico de pesquisa de conteúdos na construção e produção do conhecimento em ambientes digitais. 


\section{Webquest: das críticas às proposições}

Em um primeiro momento a WQfoi caracterizada como uma metodologia baseada na pesquisa orientada, na qual, quase todos os recursos e as fontes com que os alunos interagem para execução das atividades são provenientes da Internet. E ainda mais, as WQs tem a virtude da simplicidade(Dodge, 1995). Podem ser desenvolvidas para alunos da escola elementar à pósgraduação. E um dos principais benefícios que a WQ proporciona é de orientar o aluno no uso criativo da internet sem interferir nos rumos da pesquisa.

O uso da metodologia de $W Q$, pode ser uma alternativa pedagógica, que permite: a) garantir acesso a informação autênticas e atualizadas; b) romper as fronteiras da aula; c) promover aprendizagem colaborativa; d) desenvolver habilidades cognitivas; e) transformar ativamente informações; e) incentivar criatividade; f) favorecer o trabalho de autoria dos professores; g) favorecer o compartilhar de saberes pedagógicos(Mercado e Viana, 2004).

A WQ é organizada em cinco estruturas (Dodge, 1995; Santos, 2008) que são: (1) A introdução, que deve instigar os alunos e contextualizar o problema a ser investigado; (2) A tarefa, que apresenta as questões, os problemas e o foco da pesquisa. A tarefa é concebida como um trabalho em grupo onde cada pessoa assume diversas responsabilidades, de modo que produza aprendizagem significativa; (3) Os processos onde o professor detalha os passos, orientando os alunos no desenvolvimento da atividade como um todo; (4) Os recursos que, em sua maioria são provenientes da Web; e (5) A avaliação, que é explicitada ao aluno antecipadamente, assim esse já sabe quais serão os instrumentos e critérios de sua própria avaliação.

Vários estudos têm sido realizados sobre a contribuição desta metodologia para o processo educativo, principalmente porque as tecnologias mais avançadas, especificamente o computador, vêm adentrando no espaço escolar com muita força. Nos últimos anos, formando professores e discutindo com eles, Santos (2008) destaca alguns problemas encontrados na grande maioria das WQs analisadas, tais como: a) estrutura baseada na lógica da instrução programada; b) ênfase na disciplinaridade; c) ênfase no cognitivismo e no trabalho individual; d) a internet como repositório de informações.

No entanto, apesar de apresentar estas críticas à $W Q$, ela esclarece queos problemas levantados aqui não advêm exclusivamente da metodologia $W Q$, são dilemas epistemológicos e metodológicos próprios do modo de produção industrial, do positivismo, da tradição do currículo moderno, da mídia de massa, entre outros fenômenos da modernidade que influenciam direta ou indiretamente as práticas pedagógicas (Santos, 2008).

Em pesquisa realizada por Bottentuit e Coutinho (2008), eles destacaram que das 483 WQs em língua portuguesa avaliadas, apenas $41 \%$ foram consideradas verdadeiras WQs; e que mais da metade (59\%) destas WQs, que estavam disponíveis online entre julho e outubro de 2007, não 
passavam de folhas de exercícios com respostas fechadas e pré-definidas com o formato de uma WQ apenas, à qual Dodge(2006) denomina de "WebExercises". Isto é, atividades simples, com pouca reflexão e interatividade na produção de respostas, que apenas usam a interface da Web e a forma de WQ para reproduzir conhecimento; e que na verdade em muito se distância da idéia iniciais da WQ. Tal situação de WebExercise não conduz o aluno à produção do conhecimento, pois o esforço empreendido pelo professor na elaboração deste modelo e a atividade que o aluno fará para respondê-lo não contemplam o processo de análise, síntese e avaliação, mas apenas o ato de copiar e colar(Dodge, 1995).

As WQs devem contribuir para que os alunos aprofundem o conhecimento e refletiam no seu próprio processo cognitivo. Na construção da WQ é bom considerar as proposições de Dodge (2002) e March (2003) que é a de promover a construção colaborativa da aprendizagem, bem como permitir que os alunos cheguem a resultados abertos e/ou inesperados das tarefas propostas, para não se elaborar apenas uma folha de exercícios na Web, desprovida de interação entre os sujeitos do processo e engessada em uma única resposta pré anunciada pelo professor, ou seja, uma WebExercise. Por isso achamos importante aplicar a WQ os níveis cognitivos de aprendiz de aprendizagem da Taxonomia de Bloom para se evitar as WebExercise.

\section{WebQuest e WebExercise na perspectiva da Taxonomia de Bloom}

A Taxonomia de Bloom classifica os objetivos da aprendizagem no domínio cognitivo em 6 níveis que, geralmente, vai do nível mais simples (conhecimento) ao mais complexo (avaliação); considerando que cada nível utiliza as capacidades adquiridas nos níveis anteriores, mas que não necessariamente tenha que seguir uma ordem.

Na figura 1, abaixo, elaborada por Rocha com bases em proposições de Dodge sobre a Taxonomia de Bloom, é possível observar que o modelo de uma WQ deve abranger os níveis mais altos ou complexos de domínio cognitivo para a produção do conhecimento por parte do aluno: análise, síntese e avaliação, do contrario estará fadada a ser apenas uma WebExercise.

Como já dito anteriormente, muitas das denominadas WQ só contemplam as habilidades de pensamento de nível simples da taxonomia de Bloom, a saber: o conhecimento, a compreensão e a aplicação. Segundo Dodge (2002) na estruturação das tarefas da WQ o professor deveria levar em conta as habilidades de pensamento de nível superior. Isso, porque, nos níveis superiores ou complexos, exige-se mais elaboração na execução da WQ (Dodge, 1995) e, também, porque os alunos lembram-se mais quando aprendem a abordar um tópico desde o nível mais elevado da taxonomia. 


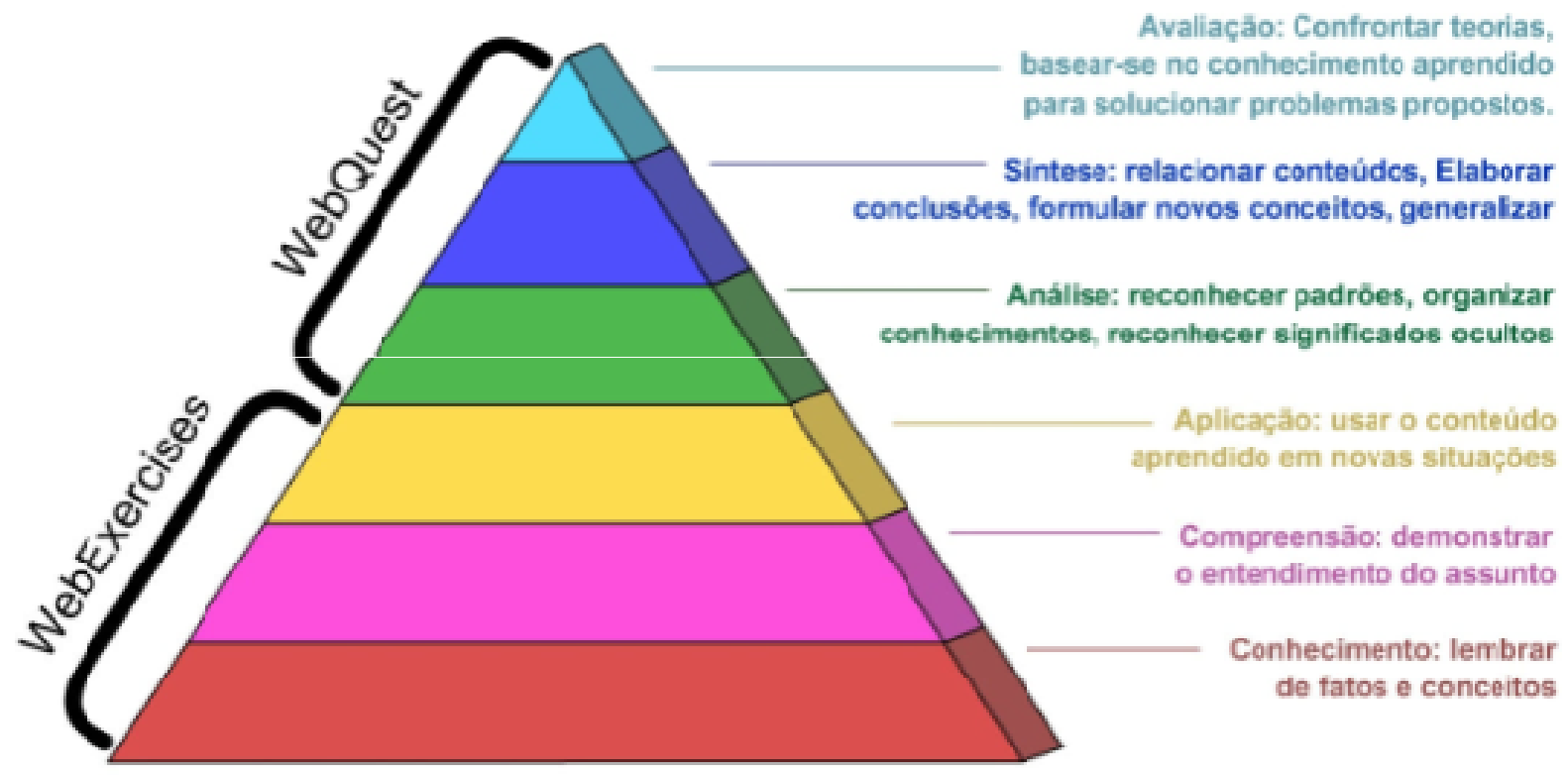

Figura 1. Relação da WQ com os níveis do domínio cognitivo

(Fonte: Rocha, 2007)

Em contrapartida, numa perspectiva de construção de conhecimentos, que ultrapassa o objetivo de uma WQ e WebExercise, queremos também discutir a WQ sob a perspectiva da Taxonomia Digital de Bloom como um dispositivo fecundo para a formação na educação online

Neste sentido, encontramos na Taxonomia Digital de Bloom - termo apresentado por (Churches, 2009) - elementos que podem nortear a elaboração das tarefas da WQ mais próxima à realidade da Web 2.0. A Taxonomia de Bloom, em sua forma original, já é amplamente utilizada pelos professores como roteiro para eles elaborarem as tarefas das WQs com alto nível de aprendizagem. Por esse motivo, introduziremos o conceito da Taxonomia Digital Bloom, concepção atualizada da Taxonomia original de Bloom, à WQ, certo de que assim poderemos trilhar caminhos que aperfeiçoarão a WQ no contexto da Web 2.0.

\section{WebQuest Interativa na Perspectiva da Taxonomia Digital de Bloom: uma nova proposição}

Acreditamos que o impacto da interação e colaboração nas suas mais diferentes formas, tem uma influência crescente na aprendizagem. E isto pode ser potencializado pelos meios digitais, que a cada dia mais se populariza, principalmente no contexto da Web 2.0, que 
representa a segunda geração da Web, com interatividade aumentada, oferecimento de hospedagem online de conteúdos, além de programas e 'suítes' que aumentam a produtividade (Litto, 2009).

Esta demanda por interação e colaboração online nos introduz, convenientemente, à relação das ferramentas atuais disponíveis na Web 2.0 a cada uma das subcategorias da Taxonomia de Bloom: recordar, compreender, aplicar, analisar, avaliar e criar.

Todavia antes de prosseguirmos é importante explicar que a Taxonomia de Bloom desde sua publicação em 1950 teve algumas atualizações, a mais recente em 2009, foi realizada pelo educador neozelandês Andrew Churchese publicado no site Eduteka sob o título Bloom's Digital Taxonomy. A Taxonomia Digital de Bloom busca atender os novos comportamentos e oportunidades de aprendizagem que tem surgido à medida que as Tecnologias da Informação e Comunicação (TICS) avançam e se tornam onipresentes.

Para Churches a Taxonomia Digital de Bloom não se restringe apenas ao âmbito cognitivo. Além dos elementos de níveis cognitivos que já trás consigo, também apresenta e relaciona métodos e ferramentas atualizadas da Web 2.0. Para o autor, a Taxonomia Digital de Bloom atende às práticas das novas tecnologias e dos processos e ações associadas a elas como também serve para alcançar os alunos digitais.

Pensando nisto, é que procuramos aplicar a Taxonomia Digital de Bloom à WQ interativa, conforme a figura 2 apresenta. Acreditamos que assim estaremos ampliando possibilidades pedagógicas no processo de ensino e aprendizagem online.

Ainda sobre a Taxonomia para a era digital, Churches (2009) esclarece que o foco não está nas ferramentas nem nas TICs, pois estas são apenas os meios e não o fim. A razão destas mídias online está em como são usadas no processo de ensino e aprendizagem para: recordar, compreender, aplicar, analisar, avaliar e criar.

Do lado operacional das WQs, é preciso ter cuidados especiais na seleção das atividades e media que vão ser vinculadas. Saber definir qual o melhor tratamento para os conteúdos que serão trabalhados e qual a melhor forma de apresentá-los a fim de alcançar os objetivos previstos. As atividades e as media da WQ servirão apenas para a aquisição e reprodução de conhecimentos ou oferecerão condições para a produção de novos conhecimentos e o posicionamento crítico dos alunos?

Quanto ao gerenciamento das mídias na educação à distância Kenskiquestiona:

É preciso pensar, também, se os estudantes serão simples usuários ou consumidores de produções já desenvolvidas, ou se terão condições de usarem os mesmos, ou outros suportes 
midiáticos, para apresentarem suas próprias criações. Ou seja, nos projetos dos cursos em EAD, planejam-se condições para que alunos e professores possam criar seus próprios jornais, revistas, homepages, vídeos, programas de rádio, ou nada disso é considerado? (Kenski, 2006).

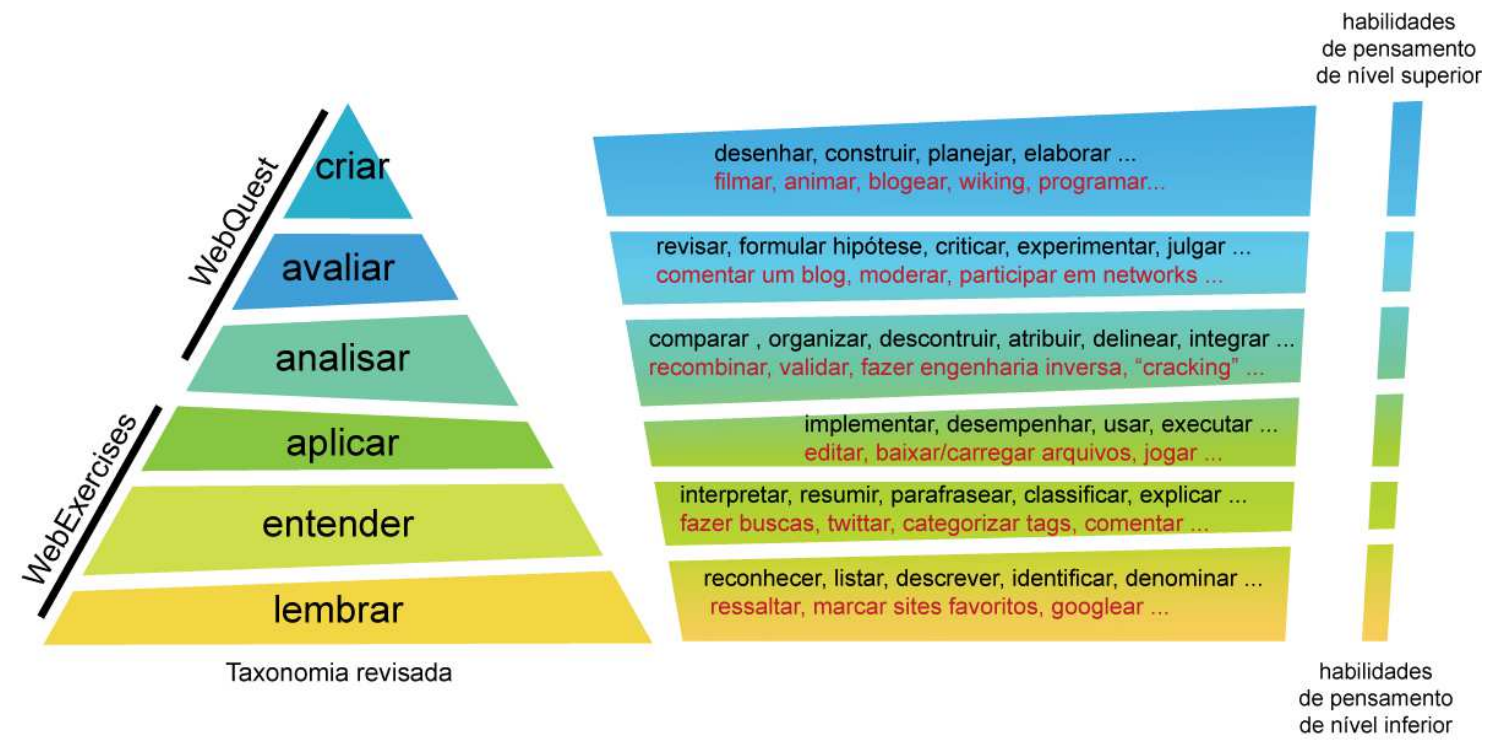

Figura 2. Taxonomia de Bloom para a Era Digital Aplicada à WQ Interativa

FONTES: Rocha (2007); Churches (2009).

Nesta perspectiva, reconhecemos que as media para criação e disponibilização das informações, e as interfaces de comunicação interativa síncrona e assíncrona são importantes tanto para a mediação pedagógica das WQs como para promover habilidades de nível superior dos alunos se bem gerenciadas pelo professor, como representa a figura 3 abaixo.

No entanto, o enfoque desta Taxonomia para a era digital não está meramente centrada nas mídias nem nas interfaces de comunicação, pois compreendemos que as ferramentas são apenas os meios para se potencializar o recordar, compreender, aplicar, analisar, avaliar e criar no processo de ensino e aprendizagem. E que mesmo a categorização das etapas nesta Taxonomia não significa que elas são hierárquicas, acreditamos que no contexto online isso não deva acontecer. $\mathrm{Na}$ verdade compreendemos que os níveis cognitivos podem transitar entre si, com certo grau de fluidez sem, no entanto perder a peculiaridade e predominância de cada nível.

As setas, na figura 3, representam a fluidez que as ferramentas online tem, podendo transitar através dos diferentes níveis cognitivos. Acreditamos que esta figura nos ajuda a compreender a mobilidade que há nas interfaces tecnológicas dependendo de como são aplicadas e exploradas no contexto online. Todavia, fazemos lembrar que geralmente um dos níveis tem maior evidência sobre o outro, dependendo como seja construído a coreografia didática no processo de aprendizagem. 


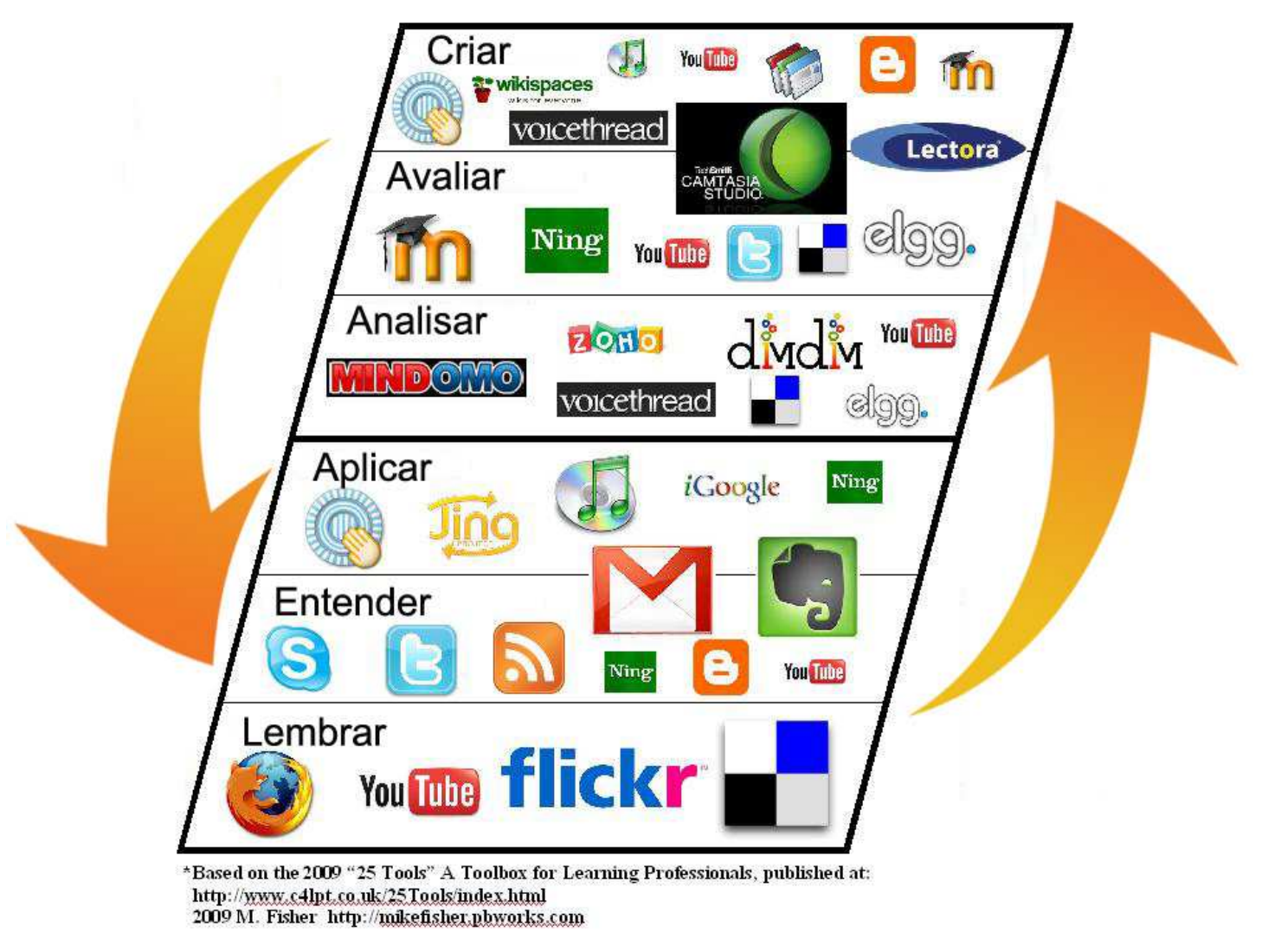

Figura 3. Recursos da web 2.0 para a Taxonomia de Bloom para a era digital.

FONTE: adaptado de Fisher (2009).

Nesta figura 3, também reconhecemos que um mesmo dispositivo tecnológico pode ou não fazer parte de determinada categoria e isto depende de como seja gerenciado sua aplicabilidade na coreografia didática. Isto fica evidenciado com a interface do YouTube $@$ que na figura 3 acima está presente em quase todos os níveis cognitivos. Neste sentido, reiteramos que na aprendizagem muitas ferramentas podem ocorrer em mais de um nível, dependendo de como seja gerenciada pelo professor e/ou aluno no desenvolvimento de seu produto final. Ora, mesmo que o professor tenha em seu desenho didático uma boa coreografia para estas ferramentas, se for mal compreendida ou executada por parte do aluno, terá sua potencialidade diminuída.

O foco, portanto, não está na ferramenta em si, mas como se faz uso delas, e a responsabilidade é de ambos, tanto do professor como do aluno. É preciso perceber que apesar destas ferramentas online serem potencializadoras para se efetivar aprendizagens de níveis cognitivos superiores, o gerenciamento metodológico voltado para o ensino e aprendizagem não 
devem ser ignorados. Isto implica em reconhecer que professor e aluno precisam estar coordenados em seus passos no uso das ferramentas da Web 2.0 para que se alcance bons resultados no processo de ensino e aprendizagem. Em se tratando dessa relação de ensinar vinculado ao estilo, tipo e forma de como os estudantes aprendem, é que dois professores da Universidade de Hamburgo, Oser e Baeriswyl (2001) usaram a metáfora da coreografia didática, para modelar tal processo e vínculo do ensino-aprendizagem. E é sobre esta metáfora que passamos a falar.

\section{Coreografia Didática}

Conforme a modelagem proposta de Oser e Baeriswyl (2001) o ensino e aprendizagem estão interligados assim como os passos de uma dança. As atitudes que o professor antecipará para sua prática darão condições ou não para que o aprendiz desenvolva seus passos, assim como os passos dos alunos irão dar condições ou não para que o professor alcance o proposto em sua coreografia didática. Sabemos que uma coreografia surge diante da necessidade de apresentar uma idéia ou sentimento a um determinado público, e que pode ser definida como a arte de composição estética dos movimentos corporais que compõem uma dança ou uma cena teatral. É neste sentido que Oser e Baeriswyl(2001)estruturam sua metáfora a partir de 4 componentes, que se complementam para se compreender esta relação vinculada do ensino e aprendizagem, como podemos ver na tabela 1 abaixo.

Tabela 1 - Os componentes das Coreografias Didáticas.

\begin{tabular}{|c|c|c|c|}
\hline \multirow{2}{*}{ Invisível } & Professores & \multicolumn{2}{c|}{ Estudantes } \\
\cline { 2 - 3 } & Antecipação & $\begin{array}{c}\text { Roteiro de } \\
\text { Aprendizagem }\end{array}$ & \multirow{2}{*}{ Invisível } \\
\hline \multirow{2}{*}{ Visível } & $\begin{array}{c}\text { Colocação em } \\
\text { Cena }\end{array}$ & $\begin{array}{c}\text { Produto da } \\
\text { Aprendizagem }\end{array}$ & \multirow{2}{*}{ Visível } \\
\cline { 2 - 3 } & Professores & Estudantes \\
\hline
\end{tabular}

A antecipação é um componente não-visível e se refere ao planejamento do docente. É o momento em que ele reflete e cogita nas possibilidades do ambiente, os estilos de aprendizagem dos alunos, e as condições do conteúdo, tudo isto com vista a promover uma coreografia de alta qualidade no sentido de antecipar os resultados de aprendizagem dos alunos.

A colocação em cena como um componente visível diz respeito a todas as ações e esforços empregados pelo professor na prática do ensino, como: a metodologia, a estrutura da aula, a tutoria, recursos ministrados, a forma de apresentação dos conteúdos e as formas de avaliação. 
O modelo base de aprendizagem ou roteiro de aprendizagem é um componente não-visível e interior, que está relacionado com as operações metacognitivas realizadas pelos alunos, diante da colocação em cena do professor, a fim de alcançar a aprendizagem. Segundo Oser e Baeriswyl as sequências deste modelo são estáveis e generalizáveis o que permite identificar suas etapas.

O Produto da aprendizagem é um componente visível e é o resultado das operações mentais e/ou práticas desenvolvidas pelos alunos e instigadas pelo professor.

A partir desses quatro componentes pode-se compreender que os professores são coreógrafos que põem em cena situações didáticas para que seus alunos aprendam. E para que essa aprendizagem seja profunda e efetiva é necessário considerar: (a) a competência do professor em planejar as situações didáticas, (b) o papel ativo dos estudantes no processo de aprendizagem e, (c) os contextos de onde nascem e se efetivam essas aprendizagens.

Padilha et al. (2009) relacionam essa metáfora à educação online, no ensino superior, na perspectiva de que, no ambiente virtual, é possível que o professor estabeleça as estratégias de aprendizagem dos seus alunos a partir das interfaces disponíveis no ambiente.

"No que tange ao ensino online, vemos cada vez mais o espaço da Educação a Distância se ampliando e proporcionando discussões profícuas sobre a docência nessa modalidade. As universidades se mobilizam para compreender uma nova dinâmica simultaneamente ao momento em que ela ocorre. As especificidades das práticas docentes no âmbito do espaço virtual e no nível do Ensino Superior acarretam modificações profundas nas compreensões sobre a didática e o processo didático neste nível de ensino" (PADILHA et al., 2009, p.34).

Acreditamos que a educação online, em sua relação com as coreografias didáticas, corresponde simultaneamente a dois tipos de demandas: por um lado, o fator de liberdade que o coreógrafo tem em criar no espaço virtual e mostrar seu repertório expressivo; e, por outro, o mesmo coreógrafo se vê limitado pelos elementos que constituem a cena coreográfica, ou seja, os recursos, as estratégias e a linguagem que o professor disporá no ambiente online irão contribuir ou não para a efetivação de seu intento.

Assim, pretendemos identificar por meio da tarefa de um WQ proposta por um professor de um curso a distância se a coreografia disposta como estratégia de aprendizagem se apresenta como uma proposta segunda a perspectiva da Taxonomia Digital de Bloom de níveis cognitivos complexos e contextualizados com a Web 2.0. 


\section{Metodologia}

Sendo este estudo em caráter exploratório, como parte de uma pesquisa de mestrado já defendida, cujo objetivo para a ocasião era a de ampliar a familiaridade com o fenômeno que se iria investigar posteriormente.

Esta pesquisa foi realizada em um Curso de Licenciatura em Letras na modalidade a distância, de uma universidade pública de Pernambuco cujo modelo específico para todas as disciplinas de todos os cursos online era a obrigatoriedade do uso de pelo menos duas WQ a cada semestre. Neste curso de Letras investigamos na disciplina de Língua Latina uma das estruturas da WQ denominada 'tarefa'. Analisamos a tarefa definida pelo professor da disciplina a partir da Taxonomia Digital de Bloom.

Segundo Dodge a tarefa é a parte mais importante, ou seja, é o coração de uma WQ. Para o autor, ela fornece o objetivo e a direção para que os alunos concentrem suas energias, como também torna concretas as intenções curriculares do professor. Uma tarefa bem concebida é atraente, e conduz ao pensar mais complexo dos alunos que vai além da compreensão do objeto proposto. A tarefa em uma determinada WQ deve sempre prezar por alcançar os níveis cognitivos mais complexo, para isso deve pensar quais as mídias fará uso no processo e no produto final que os alunos deverão apresentar ao final da WQ.

Os sujeitos de nosso estudo foram: um professor conteudista que planejou a disciplina e elaborou os materiais didáticos, um professor executor que fez acontecer a disciplina e um tutor virtual que acompanhou os alunos tirando dúvidas e dando sugestões e vinte e três alunos que cursaram esta disciplina e foram voluntários ao estudo. É importante dizer que estes alunos embora participassem de um mesmo ambiente virtual de aprendizagem, faziam parte de vários pólos de educação a distância, ou seja, residiam em municípios diversos do estado de Pernambuco.

As atividades da disciplina eram realizadas no ambiente virtual ou presencialmente nos pólos de educação a distância. Todos os passos da WQ foram disponibilizados no ambiente virtual para os alunos e eles poderiam utilizar este ambiente para discutir e organizar as atividades da $W Q$, todavia, eles mesmos preferiam fazer isso presencialmente nos pólos.

É ainda importante ressaltar que, das quatro etapas das coreografias didáticas descritas por Zabalza $(2005,2006)$ nós nos detivemos nas ações específicas do professor. A participação dos alunos neste estudo também se refere à coreografia do professor e suas ações neste sentido (antecipação, colocação em cena).Outro aspecto a se ressaltar é que o curso analisado se denomina 'semipresencial'. Entretanto, as ações analisadas neste estudo se detiveram nasocorridas no ambiente online. Por esse motivo, ainda consideramos o aspecto online do curso. 
Como nosso objetivo foi averiguar a antecipação e colocação de cena da WQ, sob a perspectiva do professor e dos estudantes, preparamos, então, seis questionários: três para a antecipação e três para a colocação em cena.

Portanto, a Tarefa deve: a) fornecer o objetivo e a direção; b) ser atraente, interessante e envolvente; c) desenvolver o pensar mais complexo, conforme a Taxonomia Digital de Bloom (Churches, 2009).

É baseado nestes indicadores que iremos fundamentar nossa interpretação final. Sendo assim, passamos a analisar a Tarefa da WQ da disciplina de Latim e suas literaturas, abaixo disponibilizada para análise.

\section{A Tarefa}

Elaborar um catálogo em que conste um repertório dos gêneros textuais produzidos pelos antigos romanos, contendo uma breve descrição e um exemplar de cada item.

Quadro 1 - Descrição da Tarefa da WQ analisada

\section{a) Fornecer o objetivo e a direção}

Afim de que o aluno saiba onde se vai chegar, a tarefa deve ser clara e objetiva tanto para os professores quanto para os alunos. A tarefa desta WQ em um primeiro momento aparenta ser objetiva, talvez por sua redação curta e por possuir direção, ou talvez por jádizer oque se deseja que o estudante produza, um catálogo. Para Padilha et al. (2009), no sentido de favorecer a mediação da aprendizagem dos alunos de educação a distância, no processo de elaboração, o texto deve ter um estilo dialógico, dirigindo-se diretamente aos alunos, deixando claros os objetivos das aprendizagens a serem construídas por estes, o que não encontramos no enunciado da tarefa, contendo um discurso impessoal.

Todavia, a partir dos questionamentos feitos ao professor conteudista, ao professor executor e aos 23 estudantes acerca do objetivo, clareza, pertinência, motivação e habilidades desenvolvidas na tarefa, as respostas foram variadas.

Para o professor conteudista:

O grande objetivo seria que o aluno seja capaz de perceber que sempre, em qualquer tempo, inclusive no tempo da civilização romana, uma sociedade funciona pela troca, produção, recepção de texto diversos, que são gêneros 
textuais diversos. Perceber isso e concretamente ser capaz de visualizar quais eram esses gêneros no caso do contexto dos romanos (Professor conteudista).

Assim, o grande objetivo era que o estudante fosse capaz de perceber e visualizar quais eram os gêneros textuais romanos. Já para a professora executora, embora os conteúdos estejam pertinentes ao currículo, os objetivos não estão tão claros para os alunos. Isto ela justifica pelas muitas dúvidas e perguntas postadas no fórum e na videoconferência, conforme a própria professora diz, quando questionada se os objetivos estavam claros:

Creio que não. Houve bastantes dúvidas dos alunos a respeito do que "eu queria" com a WQ, bem como muitas perguntas na videoconferência e no fórum tira-dúvidas. A web solicita que eles realizem um catálogo dos gêneros textuais do período do apogeu romano. Porém, os alunos não compreenderam bem, achando que deveriam traduzir textos latinos para o português ou mesmo traduzir gêneros do português para o latim (Professora executora).

Em outra situação ela ainda acrescenta:

\section{(...) porém falta orientação mais específica quanto à construção e o propósito do gênero catálogo. Também é pouco claro o que deve estar contemplado no texto de apresentação do trabalho (Professora executora).}

A falta de orientação mais específica foi discutida por Padilha (2006), que afirma que, comumente, os professores incentivam a pesquisa na Web, esperando que seus alunos encontrem o que foi proposto, sem, no entanto, dar-lhes alguma orientação pedagógica.

Percebemos que, na tarefa que deveria ser esclarecedora e objetiva, houve um certo ruído entre o professor e os alunos, na compreensão do objetivo da WQ. Para Moore (1993), este ruído é causado pela distância psicológica ou comunicacional gerada pela separação física. "Esta separação física conduz a lacunas de ordem psicológica e comunicacional originando frequentemente um espaço potencial para a existência de situações de ruído na comunicação professor-aluno (Moore apudGrof, p. 3, 2008)."

Neste sentido, os ruídos e mal-entendidos são comuns no processo de ensino e aprendizagem online, podendo aumentar ou diminuir em função do papel que o professor e aluno assumem nesta relação (Moore, 1993). Mas, do ponto de vista tecnológico atual, muitos são os recursos para se minimizar estes ruídos causados pela separação física, desde chat à conferência online face a face disponíveis na internet.

Diferentemente da perspectiva da professora executora, de que os estudantes não compreenderam qual o objetivo da WQ e que haviam se confundido pensando que era para 
traduzir os gêneros textuais romanos, os estudantes em sua maioria disseram que os objetivos estavam claros.

Dos 23 alunos questionados acerca deste tema, 15 consideraram os objetivos claros, 1 estudante disse que às vezes sim os objetivos estão claros, 2 disseram que mais ou menos, 1 outro estudante disse que nem todos os objetivos estão claros para ele, e 4 estudantes disseram que os objetivos de aprendizagem não estão claros para eles.

Acreditamos que este saldo positivo de $66 \%$ de respostas afirmando que a WQ estava clara, deu-se pelo papel que professor e aluno desempenharam: por um lado, os alunos aproximaram-se do professor por meio dos fóruns e videoconferência, como cita a professora executora:

(...) houve muitas perguntas na videoconferência e no fórum tira-dúvidas (professora executora).

E, por outro lado, o papel que a professora executora assumiu nesta relação, a fim de diminuir o ruído gerado pela falta de clareza da tarefa.

O estudante 20 diz que:

(...) e quando temos dúvidas, as tutoras nos ajudam (Estudante 20).

E o estudante 16 ainda sugere que:

(...) para um melhor êxito necessita-se de uma aproximação maior entre conteúdo, aluno e professor pela WQ (Estudante 16).

No discurso deste estudante 20, encontramos a tendência que a EAD concentra seu foco, isto é, a busca do processo de construção do conhecimento, onde o foco se concentra no desenvolvimento de uma aprendizagem ativa e colaborativa, entre professor, estudante e conteúdo. Sobre isso, Kenski (2006) comenta dizendo que nessa aproximação de professor, aluno e conteúdo no ambiente online, busca-se desenvolver comportamentos de interação, sociabilidade e comprometimento social, essenciais para a formação de bons cidadãos.

\section{b) Ser atraente, interessante, envolvente}

Depois de uma introdução, contextualizando os gêneros textuais do povo romano e suas colônias, a descrição da tarefa apresentada se resumia a apenas duas linhas dispostas na WQ, configurando um simples comando a ser executado diante da ordem do professor. O professor que planejou esta WQ não conseguiu envolver os alunos em uma situação-problema que the servisse de motivação. Apenas contextualizar como relatou o assunto desejado não é suficiente.

A tarefa deve ser desenhada na perspectiva de ser não apenas executável, mas também 
interessante para o aluno, envolvendo-o na aprendizagem. Embora a tarefa desta WQ seja executável, aparenta ser pouco interessante, uma vez que requer pouca criatividade do aluno no percurso e finalização do produto, um catálogo. O professor não criou uma situação-problema como Frade (2007) sugere dizendo que nas WQ devem sempre estar presentes elementos de sedução e motivação que, para o autor, consiste em fazer os estudantes incorporarem personagens, propor tarefas ricas, utilizar ótimas fontes ou ter como plano de fundo situações reais e relevantes para os estudantes.

Esta ausência de situação-problema (Dodge, 2002) pode ocasionar desmotivação e desinteresse aos estudantes em realizar a WQ.

E isto se percebe por meio das respostas dos alunos. Dos 23 estudantes questionados, 11 estudantes opinaram ${ }^{1}$ acerca do que acharam da WQ, 9 estudantes deram adjetivos positivos, como: bem elaborada; boa; muito boa; ótima; diferente, interessante, motivadora; empolgante; gostei; e apenas 2 estudantes deram adjetivos negativos, como: não gostou e achou a WQ chata.

O estudante 21 diz:

Achei interessante e motivadora através da curiosidade dos alunos em ter contato com uma cultura diferente da nossa (Estudante, 21).

De acordo com as respostas dos estudantes, a opinião desfavorável quanto à WQ é mínima. Neste sentido a dificuldade dos estudantes não é com a metodologia da WQ, que foi bem elogiada por eles, mas com o objetivo do conteúdo em si, que pareceu complexo e confuso.

\section{c) Desenvolver o pensar mais complexo, conforme a Taxonomia Digital de Bloom}

Pelo discurso do professor identificamos que o grande objetivo desta WQ consiste em:

(...) o aluno seja capaz de perceber que (...) Perceber isso e concretamente ser capaz de visualizar quais (...) (Professor conteudista).

Os níveis cognitivos de aprendizagens que o professor conteudista espera que seus alunos alcancem com esta WQ são: perceber e visualizar. Se comparado na Taxonomia Digital de Bloom (Churches, 2009) estes dois verbos se encontram nos níveis mais simples de habilidades cognitivas. Três estudantes confirmam este discurso do professor quando mencionaram o que eles mesmos entendiam como objetivo da WQ.

(...) pois é muito difícil compreender todos (gêneros textuais) e ainda mais,

${ }^{1}$ Como para este questionamento havia duas perguntas - O que você achou da WQ? Entendeu o que era para fazer? - os 23 estudantes, por opção própria, ou respondiam a primeira questão ou então a segunda, raramente as duas perguntas ao mesmo tempo. Por isso, dos alunos que responderam a primeira parte do questionamento $O$ que você achou da WQ? foram apenas 11. 
quando temos que estudar sozinhos

(Estudante 13).

(...) acredito que seria nos mostrar que independente de qual seja a língua todas tem suas diversidades de gêneros (Estudante 15).

(...) conhecer os gêneros textuais que circulavam na Roma antiga e saber, dentre eles, quais continuam em circulação até os dias de hoje (Estudante 21).

Os níveis cognitivos de aprendizagens mencionados pelos alunos foram: compreender, mostrar e conhecer. E, assim como os níveis cognitivos de aprendizagens explorados pelo professor conteudista, aqueles se aplicam aos níveis mais elementares da Taxonomia Digital de Bloom (Churches, 2009).

Portanto, concluímos que o nível cognitivo desses verbos explorados encontra-se nos níveis mais simples na escala da Taxonomia Digital de Bloom, ou seja, em recordar e compreender. Isto leva-nos a inferir que esta WQ tem uma coreografia mais para uma WebExercise do que uma WQ interativa, pois não explora os níveis cognitivos mais complexos, como: analisar, avaliar e criar (Rocha, 2007). Na antecipação da WQ o professor envolvido em sua elaboração deve considerar a Taxonomia Digital de Bloom (Churches, 2009) como parâmetro para que se obtenha uma WQ que proporcione aos estudantes aprendizagens motivadoras e contextualizadas em relação à Web 2.0, principalmente se considerarmos que é uma WQ para um curso online.

Ainda é na tarefa que identificamos o que o professor planeja para que seus alunos produzam e apresentem como produto final da WQ. E é pelo produto final que o professor identifica se o aluno compreendeu e alcançou o nível de aprendizagem planejado em sua antecipação.

Como produto final desta WQ, os alunos deveriam criar um catálogo dos gêneros textuais do período do apogeu romano, contendo uma breve descrição e um exemplar de cada item. Um catálogo é a relação ordenada de coisas ou pessoas com descrições curtas a respeito de cada uma.

Para se elaborar um catálogo, o roteiro de aprendizagem planejado pelo professor conteudista e tomado pelos alunos foi: a) identificar - repertório dos gêneros textuais; b) elaborar - elaborar um catálogo; c) listar - de cada item; d) descrever - contendo uma breve descrição; e) representar - um exemplar.

Estas habilidades cognitivas propostas nesta antecipação do professor são consideradas, na Taxonomia Revisada de Bloom (CHURCHES, 2009), como habilidades de nível mais simples, ou seja, em lembrar e entender.

Neste sentido o produto final de uma WQ que se caracterize como uma metodologia que 
corresponda ao contexto da Web 2.0, deve favorecer aos níveis de pensamentos mais complexos, conforme é apresentado na Taxonomia Digital de Bloom (Churches, 2009). E não se limitar em orientar os alunos na pesquisa, solicitando apenas uma mera reprodução da informação encontrada nos sites, parecendo muito mais uma busca por respostas pré-definidas do que um propósito de estimular a aprendizagem por investigação e trabalho coletivo, que deveria ser o objetivo de uma WQ (Bottentuit; Coutinho, 2008).

Quanto à aplicabilidade da WQ ao contexto online no qual o curso está inserido, percebemos discrepância no sentido de que se deveria promover o uso dos meios mediáticos para a execução da tarefa bem como para o produto final, conforme a Taxonomia Digital de Bloom esclarece nas figuras 2 e 3.0 produto final desta WQ ainda está engessado ao modelo tradicional de apresentação de trabalho. Ou seja, o aluno depois de sua pesquisa apresenta o produto em forma de relatório, bem visível, quando na tarefa apenas se pede para "elaborar um catálogo" e não se sugere um processo criativo para essa elaboração.

Nesta tarefa, o produto final poderia ter sido mediado por uma das mídias da Web 2.0 vista pela Taxonomia Digital de Bloom através da qual se poderia explorar as ações: filmar, bloguear, animar e outras que se enquadram nos níveis mais complexos e que exigem mais criticidade, criatividade e interatividade entre os alunos. No entanto, também reconhecemos que, como a Taxonomia Digital de Bloom é muito recente e pouco difundida, não é de conhecimento da maioria dos professores que tentam se apropriar da metodologia da WQ.

\section{Considerações}

Quanto às respostas dos professores e estudantes, os significados que emergiram destas nos faz julgar que planejar uma WQ não é tarefa fácil, principalmente para profissionais que não tiveram o devido preparo didático e pedagógico para realizar esse tipo de atividade - realidade que muitos docentes do ensino online enfrentam com frequência.

No que tange à coreografia didática do professor, a falta de uma antecipação adequada e bem planejada, que explicite com clareza o conteúdo e as tarefas, pode levar os professores diretamente envolvidos no processo de execução da $W Q$, ou seja, na colocação em cena da mesma, a enfrentar, de alguma forma, um certo grau de ansiedade ao perceber que seus estudantes não estão alcançando o nível de desenvolvimento esperado; e os estudantes, por sua vez, podem acabar desmotivados por não conseguirem perceber ou por não alcançarem uma compreensão adequada do objetivo pretendido, da importância do conteúdo abordado e das técnicas que devem ser por eles utilizadas para resolver o problema que uma WQ propõe.

Considerando que a metodologia da WQ é usada em processos colaborativos de aprendizagem, e que deve valorizar o diálogo e a participação dos envolvidos, como um roteiro 
metodológico criativo de pesquisa de conteúdos na construção e produção do conhecimento, ainda entendemos que ela pode ser uma excelente estratégia de ensino e aprendizagem colaborativa, entretanto, precisa ser mais explorada na modalidade de educação online, no contexto da Web 2.0.

No entanto, a tarefa da WQ analisada não segue os padrões mínimos de qualidade no tocante Taxonomia original de Bloom que Dodge sugere e muito menos à Taxonomia Digital de Bloom. Quanto aos verbos usados limita-se a explorá-los no âmbito cognitivo simples da taxonomia, o que nos levar a considerar a metodologia analisada como uma WebExercise.

Observamos que seria necessária uma maior adaptação das atividades às mídias da Web 2.0 para que seja possível classificar a WQ analisada como uma WQ Interativa na perspectiva da Taxonomia Digital de Bloom. A antecipação por parte do professor das Tarefas deve levar em conta os verbos e ferramentas propostos na figura 2 e 3 como aplicabilidade da Taxonomia Digital de Bloom. Também seria necessário ampliar as possibilidades de atividades em grupos, que gerassem atitudes colaborativas e integradoras entre os alunos, buscando motivar a construção de um conhecimento crítico, criativo e colaborativo na modalidade de ensino online por meios das ferramentas da Web 2.0.

Nesse sentido, consideramos que os professores precisam conhecer mais a metodologia da WQ e a Taxonomia Digital de Bloom levando em conta em sua coreografia didática: melhorar a aprendizagem colaborativa dos alunos; melhorar as relações sociais do grupo de estudantes; melhorar e incrementar o uso dos recursos que a Web 2.0 disponibiliza como um recurso a mais na aquisição do conhecimento; melhorar espaço para a co-autoria de sentidos e significados entre os estudantes, bem como fazer uso da linguagem em tom dialógico em que possa aproxima o aluno aos passos do professor nessa coreografia didática.

\section{Referências}

Bottentuit Junior, J.B. \& Coutinho, C. P. Análise dos Componentes e a Usabilidade das Webquests em Língua Portuguesa. Disponíveis na Web: um estudo exploratório. 50 CONTECSI Congresso Internacional de Gestão de Tecnologia e Sistemas de Informação. São Paulo, 2008.

Churches, Andrew.Bloom's Digital Taxonomy. 2009. Disponível em http://edorigami.wikispaces.com/file/view/bloom's+Digital+taxonomy+v3.01.pdf, acessado em 05 de dezembro de 2009.

Dodge, B. WebQuests: A Technique for Internet - Based Learning. The DistanceEducator, V.1, no 2. 1995. 
WebQuests: past, presentand future. In: Carvalho, A. A. (Org). Actas do encontro sobre WebQuest. Braga: Univerdidade do Minho-PT, 2006.

WebQuest Taskonomy: A TaxonomyofTasks. 2002. Disponível em

<http://webquest.sdsu.edu/taskonomy.html > acesso em 17 setembro 2010.

Fisher, Mike. Visual Bloom's. 2009. Disponível em

http://visualblooms.wikispaces.com/page/diff/home/168742529 acessado em 10 jan. 2011.

Grof, Luciana et al. A Teoria da distancia transactional - Michael Moore. UniversidadeAberta, Portugal. 2008.

Kenski, Vani Moreira. Gestão e Uso das Mídias em Projetos de Educação a Distância. Revista ECurriculum, São Paulo, v. 1, n. 1, dez. - jul. 2006. Disponível em:

http://www.pucsp.br/ecurriculum, acesso em: 10/05/2010

Litto, Fredric Michael. $O$ atual cenário internacional da EAD. In: Litto, Fredric; Formiga, Marcos. Educação a distância. O estado da arte. São Paulo: Pearson Education do Brasil, 2009. p. 14-20.

March, T. The Learning Power of WebQuests. EducationalLeadership, 61 (4), pp.42-47. 2003.

Mercado, L.P.L.e Viana, M.A.P. Projetos Utilizando Internet: A. Metodologia WebQuest na

Prática. Maceió-AL: Q Gráfica/Marista. 2004.

Moore,G. Michael. Theory of transactional distance.in Keegan, Desmond, Theoretical Principles of Distance Education.Routledge, London.1993. Disponível em:

<http://www.aged.tamu.edu/research/readings/Distance/1997Moore TransDistance.pdf> Acessado em 21 janeiro 2011.

Oser, F. K. E Baeriswyl, F. J. Choreografiesofteaching: bridginginstruction to teaching. In V. Richardson (Editor): Handbookofresearchonteaching (4a ed). Washington: AREA, 2001. pp. 10311065.

Padilha, Maria A. S. Pesquisa de conteúdos na Web: copiar e colar ou estratégia para construção do conhecimento? 2006. Tese (Doutorado em Educação) - Centro de Educação, Universidade Federal de Pernambuco, Recife, 2006.

et al. Ensinagem na docência online: Análise das estratégias docentes à luz das coreografias didáticas. In: 70 Encontro de Educação e Tecnologias da Informação e Comunciação - VII ETIC, Rio de Janeiro, 2009.

Rocha, L. R. A Concepção de Pesquisa no Cotidiano Escolar: Possibilidades de Utilização da Metodologia WebQuest na Educação pela Pesquisa. Dissertação de Mestrado em Educação Curitiba: Universidade do Paraná. 2007. 
Santos, Edméa. O. A metodologia da WebQuest interativa na educação online. In: Freire,

Wendel. (Org.). Tecnologia e educação: as mídias na prática docente. Rio de Janeiro: WAK Editora, 2008 , v. 1, p. 107-128.

Zabalza, M. A. La didactauniversitaria. Conferência pronunciada na

PontificiaUniversidadJaveriana de Cali, em 9 de fevereiro de 2005. Disponible em < http://portales.puj.edu.co/didactica/Archivos/Didactica/DIDACTICAUNIVERSITARIA.pdf > Acessado em 27 outubro 2010.

La universidad y ladocenciaenel mundo de hoy. Bogotá: Publicación de laPontificiaUniversidadJaveriana. 2006

Rogério Antonio de Paiva. Marinha do Brasil. Atualmente é professor efetivo de Inglês da Marinha do Brasil. Mestre em Tecnologia da Educação (UFPE).rogeriopaiva5@gmail.com

Maria Auxiliadora Soares Padilha. Programa de Pós-Graduação em Educação Matemática e Tecnológica Universidade Federal de Pernambuco. dorapadilha@gmail.com 